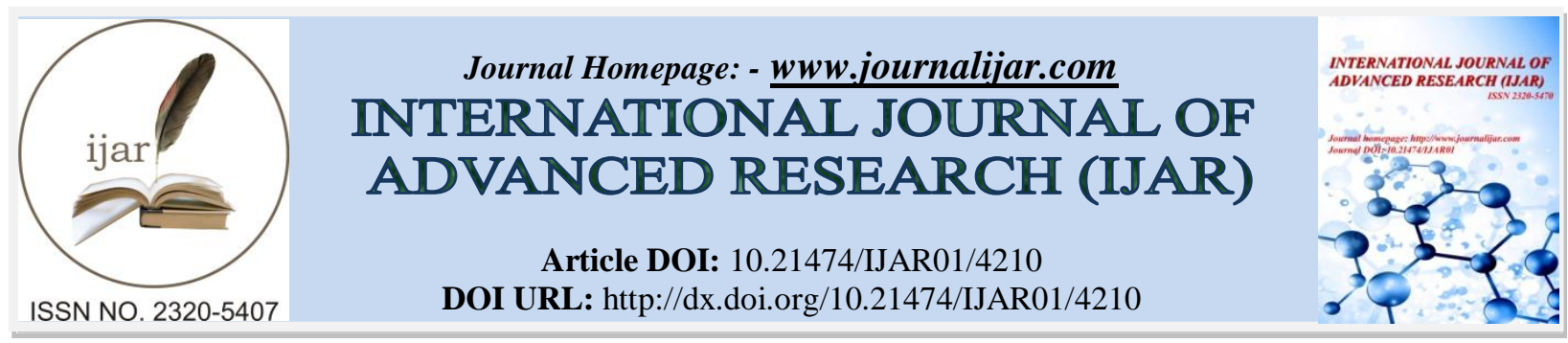

RESEARCH ARTICLE

\title{
AN EMPIRICAL STUDY ON INVESTORS ATTITUDE TOWARDS INVESTMENT WITH SPECIAL REFERENCE TOWARDS INVESTORS OF HOSHIARPUR CITY, PUNJAB.
}

Asst. Professor, St. Claret College, Bangalore.

\section{Dr. Harmeet Matharu.}

\section{Manuscript Info}

Manuscript History

Received: 19 March 2017

Final Accepted: 17 April 2017

Published: May 2017

Key words:-

Investment, Investor, Attitude.

\section{Abstract}

All investments are risky, as the investor parts with his hard earned money. An efficient investor with a proper training can reduce the risk and maximize profits. Investors have a lot of investment avenues to park their savings. The risk and returns available from each of these investment avenues differ from one avenue to another. The investors expect more returns with relatively lesser risks. A proper understanding of money, its value, the available investment avenues, various financial institutions providing the facility of investments, the rate of return/risk, etc., are very important to successfully manage one's finance for achieving future goal. Many people are not willing to take risk for their funds, so many prefer to invest in bank deposits, insurance, post office saving etc. Many of the people are not aware about how to make an investment in share market, equity etc. "No pain no gain" it is the golden principle of investment management. The study basically focuses on the various investment avenues available to the investor, factors considered for investment. People now days are not ready to bear risk, but at the same time more risk leads to more profit. Investors cannot avoid risk but they can minimize the risk by investing their money in various types of investments so that they can get a moderate profit. This study basically provides awareness among people about various investment avenues available to them and what factors they should consider before making an investment.

\section{Introduction:-}

Investment refers to acquisition of some assets. It also means the conversion of money into claims on money and use of funds for productive and income earning funds for securing some objectives like income, appreciation of capital gains, or for further production of goods and services with the objective of securing profits. Investment is putting money into an asset with the expectation of capital appreciation, dividends, or interest earnings. Most or all forms of investment involve some form of risk, such as investment in equities, property, and even fixed interest securities which are subject, among other things, to inflation risk. A good investment strategy will diversify the portfolio according to the specified needs. The investor has to choose Proper Avenue depending upon his specific need, risk preference, and returns expected. 
The Different investment avenues are:-

- Safe/Low Risk Avenues: Savings Account, Bank Fixed Deposits, Public Provident fund,

- Government Securities, etc.

- $\quad$ Moderate Risk Avenues: Mutual Funds, Life Insurance, Debentures, Bonds.

- High Risk Avenues: Equity Share Market, Commodity Market, FOREX Market.

- Traditional Avenues: Real Estate, Gold/Silver, Chit Funds.

The investors should have full knowledge of the investment options in order to avoid any loss in future. The investor should be alert what, where, why, when and how to make investment in different investment options.

\section{Different modes of Investments are as follows:-}

- Corporate bonds/ debentures

- Public sector bonds

- Preference shares

- Equity shares

- National savings schemes and certificates

- $\quad$ Provident funds

- Corporate fixed deposits

- Life insurance policies

- Unit schemes of Unit trust of India

- Post office savings bank account etc...

Alternative investments:-

Alternative investments are sometimes used as a tool to reduce overall investment risk through diversification. Some of the characteristics of alternative investments may include:

- Low correlation with traditional financial investments such as stocks and bonds.

- It may be difficult to determine the current market value of the asset.

- Alternative investments may be relatively illiquid.

- Costs of purchase and sale may be relatively high.

- There may be limited historical risk and return data.

- A high degree of investment analysis may be required before buying.

\section{Review of Literature:-}

* Madhumathi.R (1998) in her study entitled "Risk Perception of Individual Investors and its Impact on their Investment Decisions" examined the risk perception of 450 individual investors, selected at random from major metropolitan cities in India, dividing them into three groups as risk seekers, risk bearers and risk avoiders. The major findings of the study revealed that majority of the investors were risk bearers and they had the tendency to use the company's performance as a basic factor to take investment decisions. They also depend on the advice of share brokers and investment consultants. The risk seekers generally took decisions based on market conditions, industrial positions and social changes. They relied on newspapers and reports for information. Risk avoiders did not have any specific traits. They were very objective and looked for facts and certainty in their investment decisions. They relied on the advice of their friends and relatives.

* A survey was conducted by "Intelligent Investors" (A Fortnightly magazine) (1998) about the home instincts of investors. The survey was intended to disclose the average Indian's attitude to housing, living space and real estate. Forty Per cent of male category opted for 500-800 square feet spacious house to a family of four members, whereas 50 Per cent of female respondents needed a house of 801-1200 square feet. Sixty Per cent of Chennai based respondents preferred even smaller space (500-800. sq. feet) for a family of four members, 34 Per cent of male and 28 Percent of female respondents expressed their willingness to have a house of their own even before their marriage. But among the total respondents, 34 Per cent wanted their own house after having children. Fifty eight per cent of Calcutta based respondents and 48 Per cent of Chennai based respondents were willing to own a house atleast before their retirement.

* An All India Survey titled (1998) "Household Investors" Problems, Needs and Attitudes conducted by The Society of Capital Market Research and Development revealed the fact that majority of the retail investors lost confidence in various agencies like SEBI, credit rating agencies etc, A cross section analysis showed that 79 per cent of investors had low confidence or no confidence in company management, 55 per cent in SEBI, 64 per 
cent in auditors and 78 per cent in share brokers. The study noticed a significant shift of investors from equity shares to high quality of domestic financial instruments. However, bonds were still far behind shares in terms of market penetration. An important note was that a majority of retail investors were not influenced by credit rating and also expressed their confidence in these agencies.

\section{Purpose of the Study:-}

The basic purpose of the study is to have an insight into different investment avenues available for an investment. To understand the preferred investment avenues among the people. To understand the awareness level of the people on various investment opportunities, factors considered for investment. In today's competitive environment a lot of investment avenues are being provided by various Public and private financial organizations, people are totally confused to decide where to make an investment.

\section{Objectives:-}

- To find out the main objective of investor towards investment.

- To understand the various investment avenues available for people to make an investment.

- To understand and analyze the preferred investment avenues among the people.

- To understand and analyze the factors considered for making an investment.

- To understand the awareness level of the people about various investment avenues.

\section{Research Methodology:-}

The study was carried out with the help of primary data and secondary data for the purpose to analyze and understand the preferred investment avenues by the people and factors considered for investment.

\section{Data Collection:-}

The present study is mainly based on primary data and secondary data. The required data were collected through questionnaire and documents, certain web sites and other online data bases etc.

\section{Sources of Data:-}

Primary data was collected through questionnaire and Secondary data was collected from the reports, articles, journals, documents, printed literatures, certain web sites and other online data bases etc.

\section{Tools of Analysis:-}

Various tools were used for the analysis and interpretation of data. Data was gathered by using questionnaire. Data is representation through charts.

\section{Sample Size:-}

The study has taken around 50 respondents who are the part of working population in Hoshiarpur city. The investors are selected by convenient sampling method.

\section{Scope of the Study:-}

This study was mainly planned to understand the various investment opportunities available for people and also to understand the preferred investment avenues. This research study surely will provide a parameter particularly for a better understanding of the investment avenues available to an investor from various financial institutions.

\section{Analysis And Interpretation:-}

Personal Profile of the People

\section{An industry the respondents do work with:-}

Among the respondents $50 \%$ belongs to the education sector and technology sector, followed by $28 \%$ belonging to automotive sector, $10 \%$ belongs to Hospital sector, $8 \%$ is related to banking and insurance sector and $4 \%$ belong to other sector like market research and analytics. 


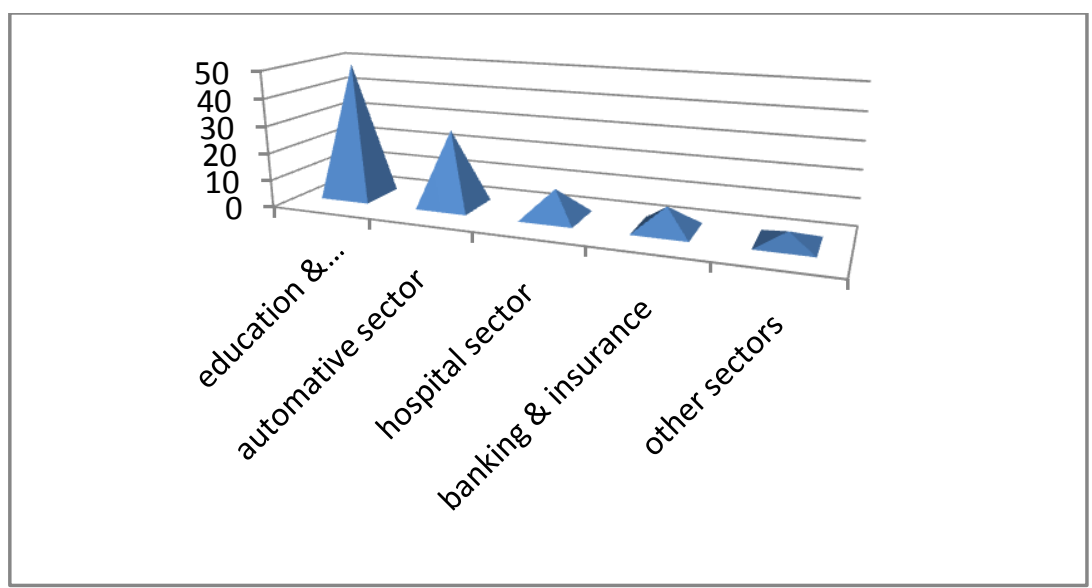

The Age of the people:-

Among the respondents $25 \%$ belong to age category of $25-35$ years, followed by $50 \%$ in $36-45$ years category, $6 \%$ in age group below 25 years and $19 \%$ in $46-55$ years of age.

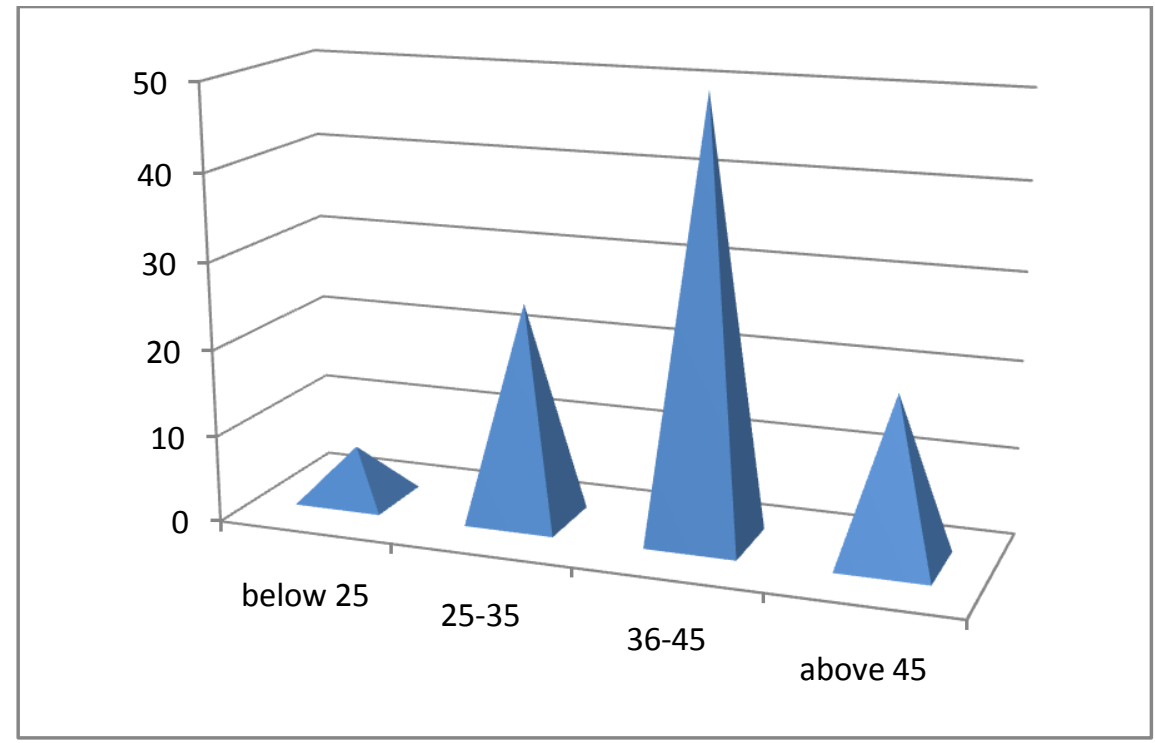

\section{Educational Qualification:-}

Among the respondents $40 \%$ of the respondents are post graduate, $32 \%$ of the respondents hold graduation degree, $25 \%$ is professionals and $3 \%$ are undergraduate. It is observed that maximum of the respondents are post graduates, followed by graduates and professionals whereas the minimum are undergraduates 


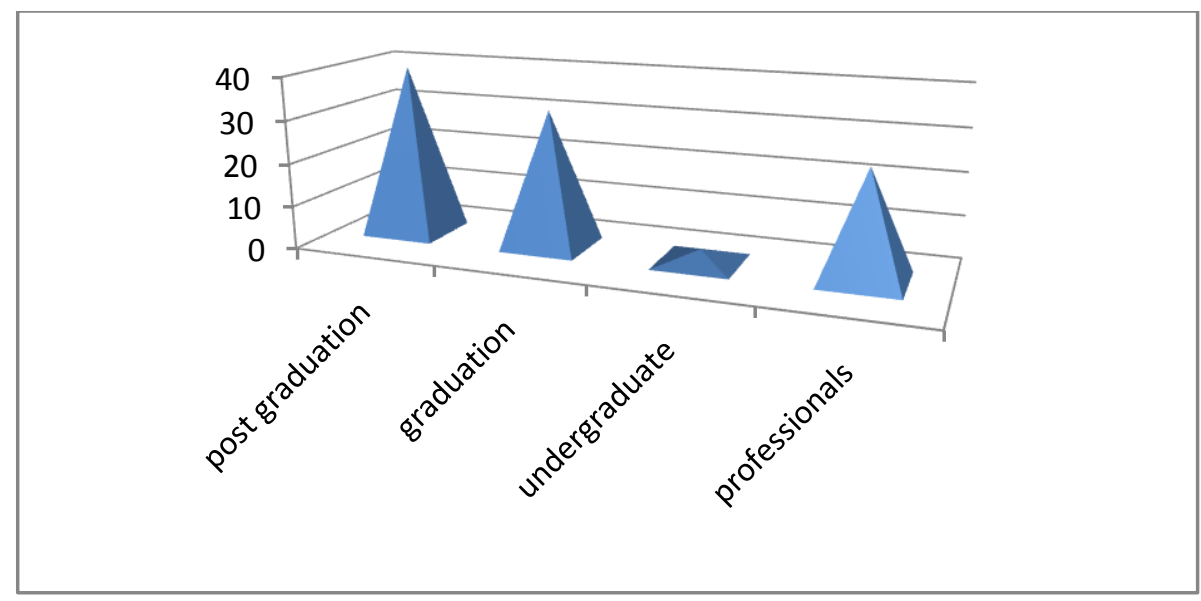

\section{Annual Income:-}

Among the respondents, $55 \%$ of the respondent's annual income falls between 1.5 to 3 lakhs pa, followed by $20 \%$ respondents annual income falls under 1 to 1.5 lakhs per annum, $20 \%$ of the respondents income fall under 3lakhs and above and $5 \%$ of the respondents income fall under below 1 lakh.

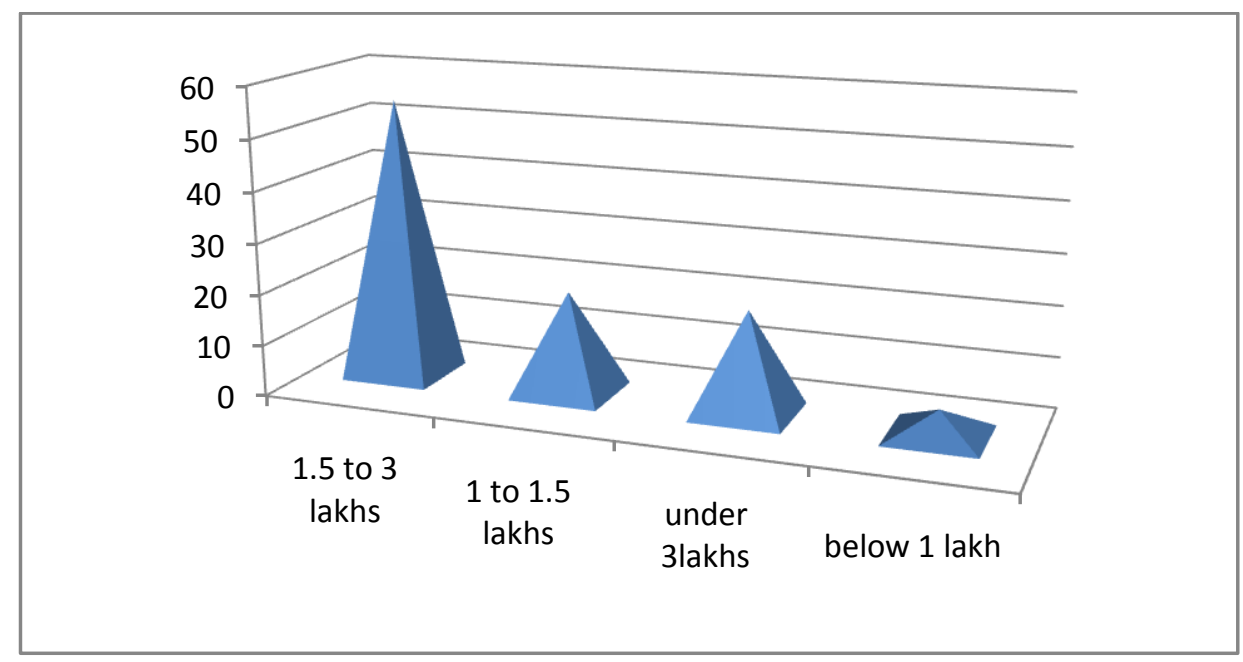

Awareness Level among People about Various Investment Avenues:-

Among the respondents who are aware about the various investment options available to them for investment are about $80 \%$ and those who are not aware about the various investment avenues is about $20 \%$ This chart clearly indicates that some respondents must be made aware about the investment options, its advantages etc.

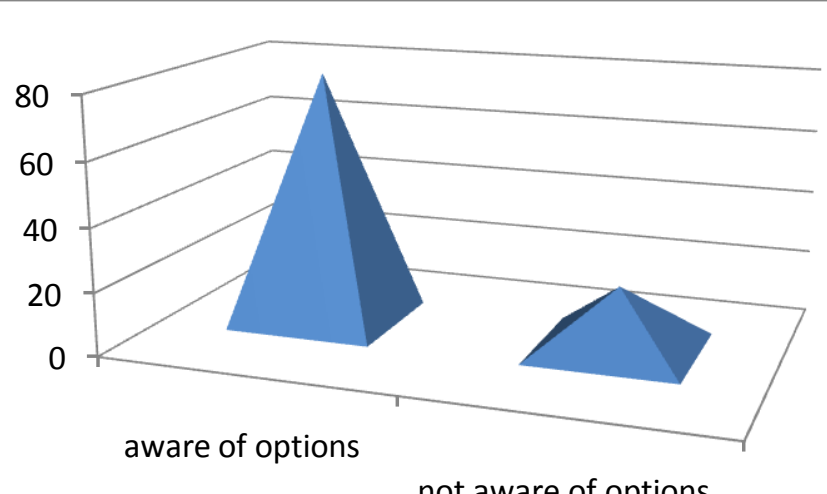




\section{People Prefer To Invest Their Funds In The Following Investment Avenues:-}

From the diagram it is stated that $20 \%$ of the people prefer to make investment in fixed deposits followed by $20 \%$ in insurance sector, $30 \%$ in mutual funds, $10 \%$ in real estate, $5 \%$ in post office savings and $5 \%$ in share market.

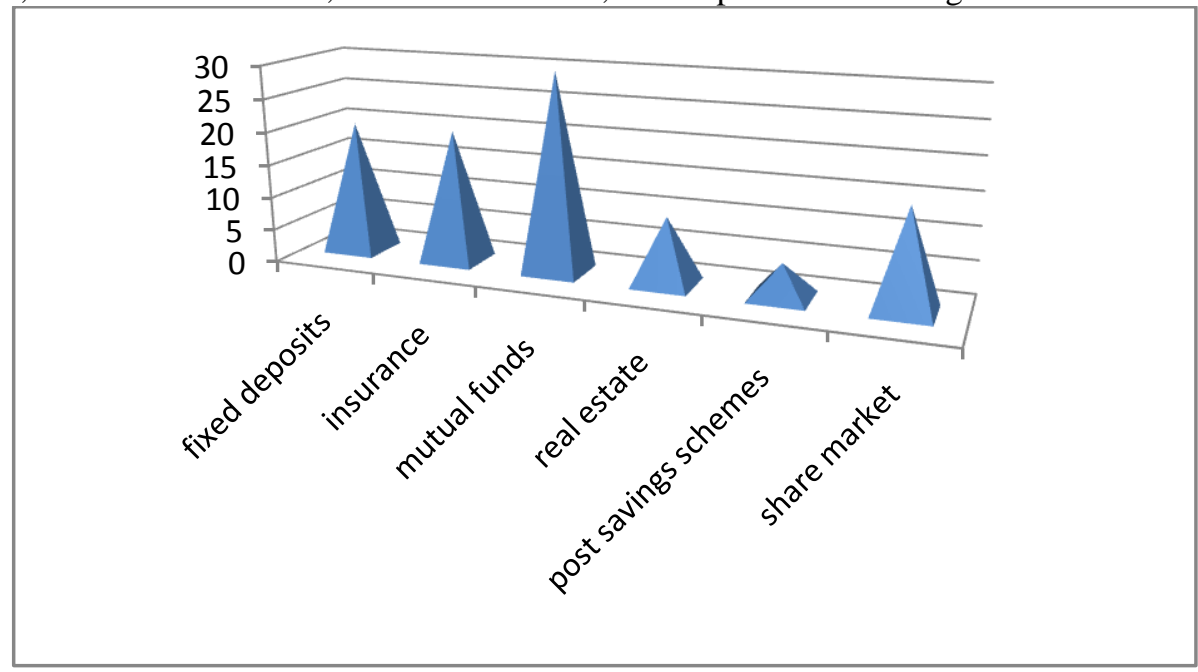

\section{Factors Considered By People For Making An Investment:-}

From the chart it is stated that among people the most important factor they consider before making investment is the returns followed by risk, locking period, type of investment option and minimum investment amount. The people have rated the following factors out of 10 which gave the rating as follows Returns (8/ 10), Risk (7/ 10), Locking Period (6/ 10), Type of Investment Option (5 / 10), and Minimum Investment Amount (5/ 10).

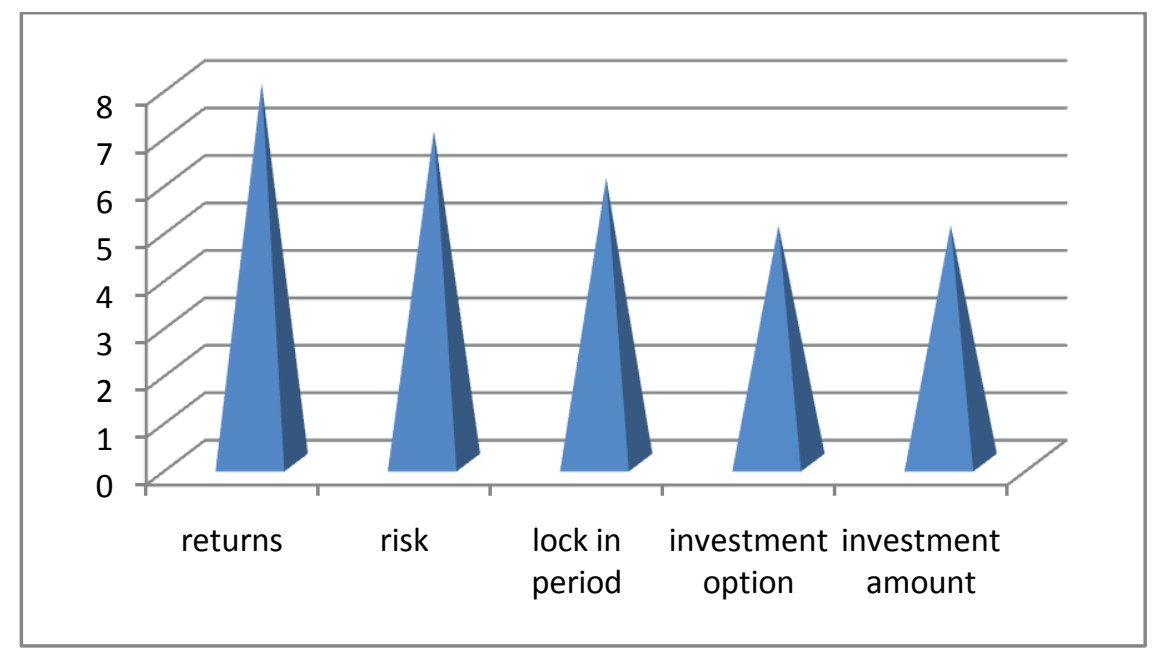

\section{Percentage Of Annual Income People Wish To Invest:-}

Among the respondents who wish to invest in future as a part of their annual income is: $40 \%$ of the respondents wish to invest around 10-20\% and also below, $25 \%$ of the respondents wish to invest around $21-30 \%$, 20\% wish to invest $31-40 \%$ and $15 \%$ above $40 \%$ of their annual income. 


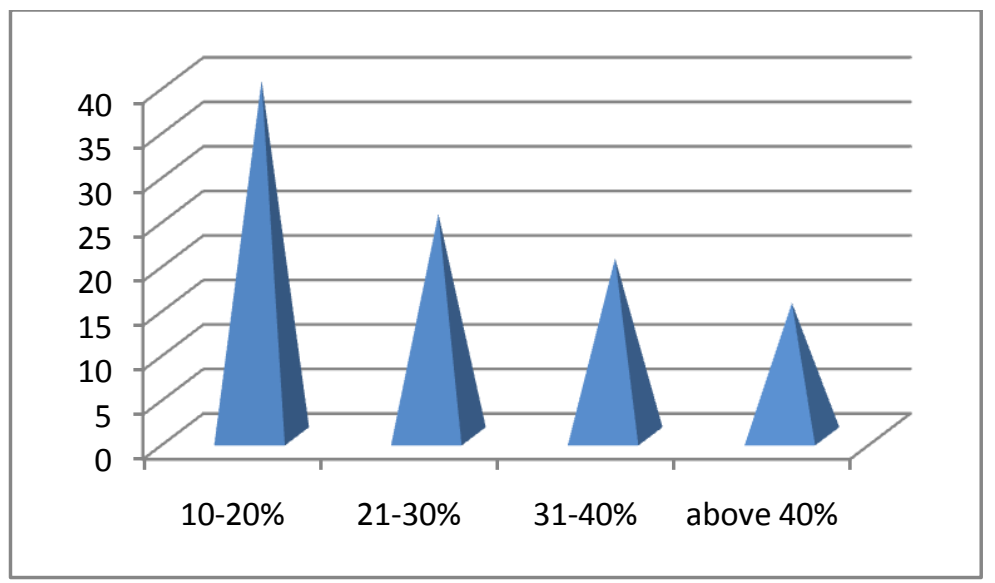

The Opinion People Would Consider Before Making An Investment:-

Majority of the respondents prefer to ask their family members (50\%) before making an investment, followed by their own decision (30\%), then the financial consultants (10\%), friends (5\%), through advertisements and other reasons $(5 \%)$.

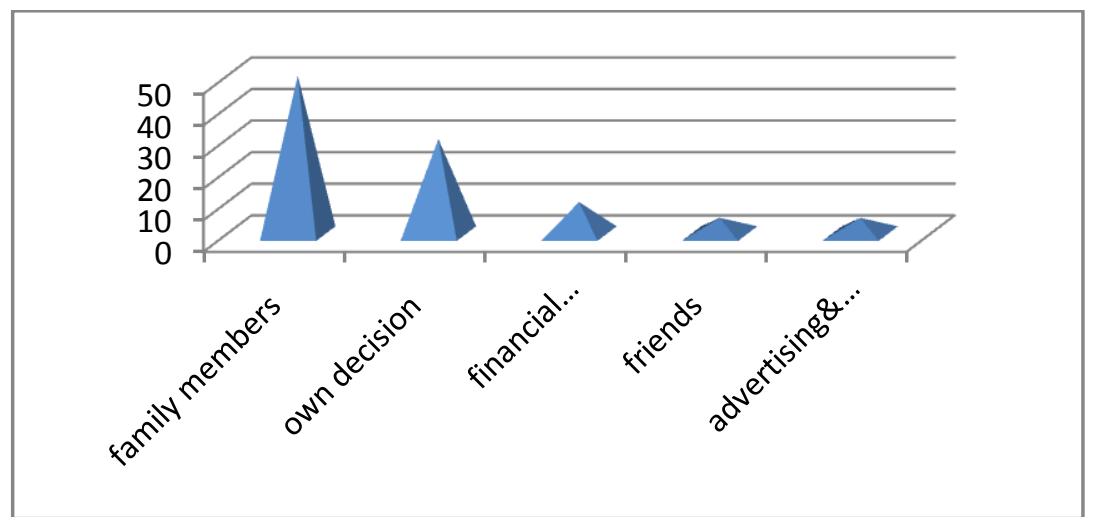

\section{People Prefer To Invest For Long, Medium Or Short Term:-}

Among the respondents $40 \%$ of them are interested to make investments either for a period of medium term or short term, $30 \%$ of the respondents would like to make an investment with a combination of short and long term and also a combination of medium and long term. $20 \%$ respondents would like to make investment alone for a long term. $10 \%$ of the respondents would like to make investment in combination of short, medium and long term investments rather than making investment only for long term.

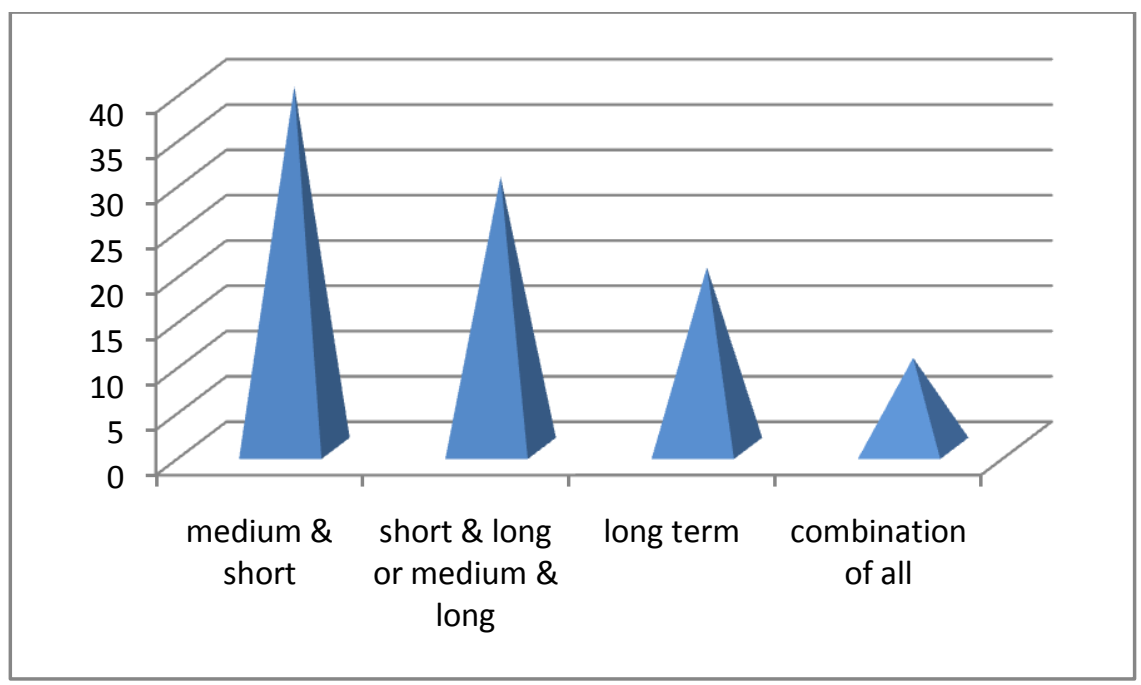

The Investment Option Which Has Less Risk:- 
According to the respondents $55 \%$ of them say investing with bank deposits is less risky, as they have ability to provide reasonable returns \& the money invested is locked in safely. Next investment which is less risky is post office deposit $(27 \%$ ) which not commonly used still some respondents prefer it because of its safety followed by insurance $(10 \%)$ and real estate $(3 \%)$. Only $5 \%$ of the respondents are ready to invest in stock markets as they consider themselves to be risk takers.

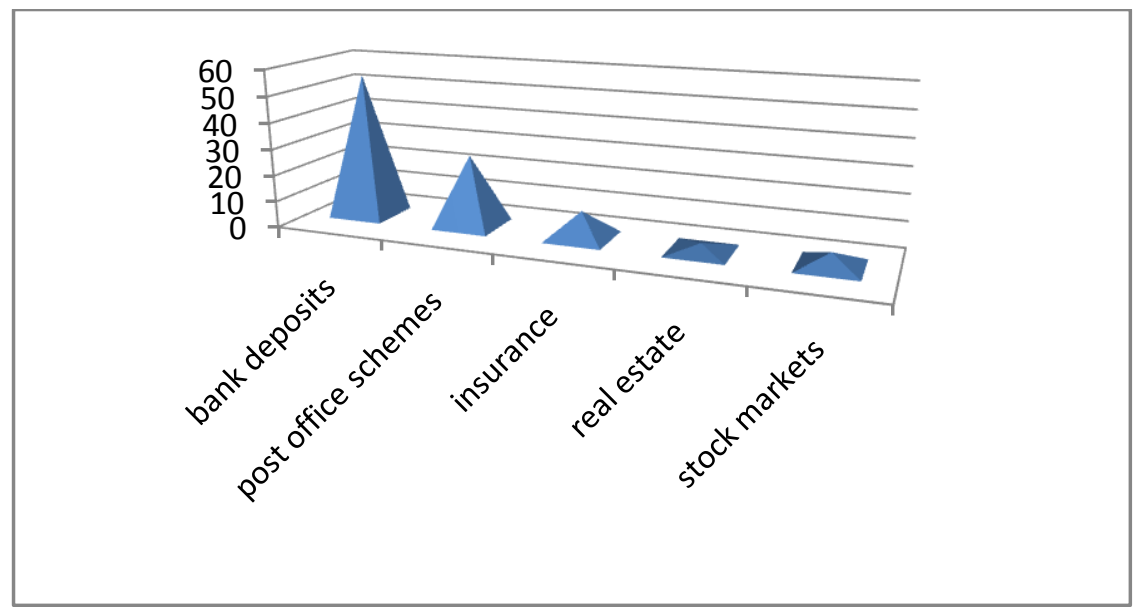

Purpose Of Making An Investment:-

Among the respondents the reasons for making investment is basically to secure their future savings (40\%) followed by children education (20\%).Many of them gave the response as wealth creation (10\%), Retirement (25\%) and for marriage $(5 \%)$.

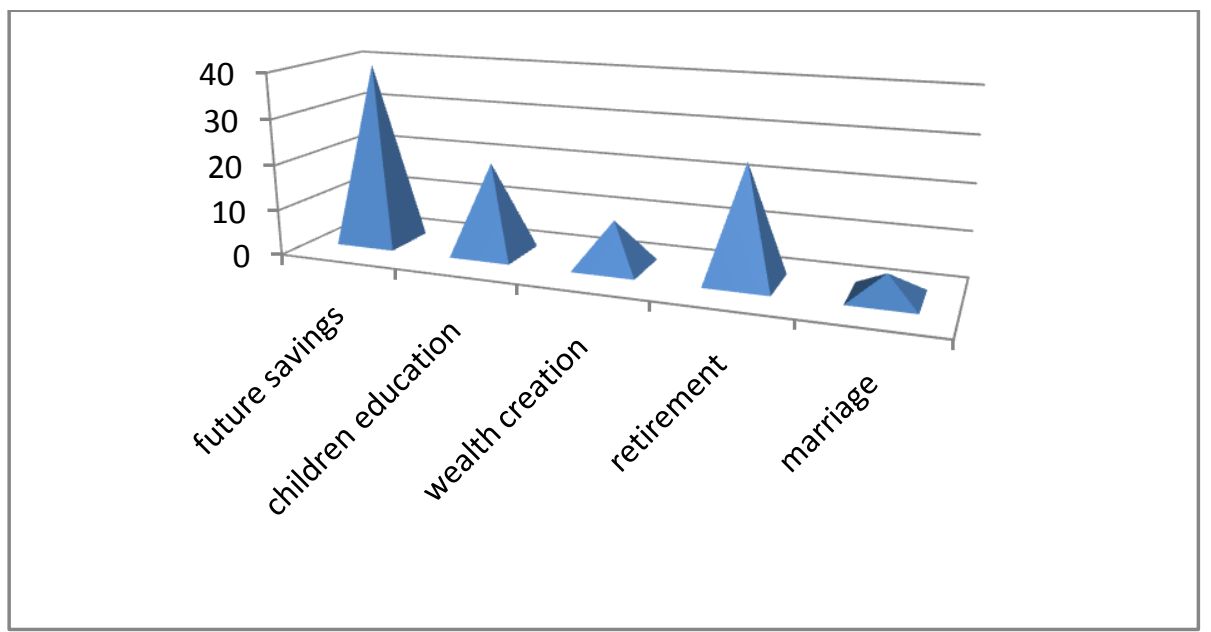

\section{Reasons For Not Investing In Share Market:-}

Among the respondents the reasons for not making an investment in share market is for the few reasons such as lack of knowledge (55\%), which means they don't know the dealings in share market in order to earn profits, Many of them have stated that because of risk factors (30\%) and others because they are not assured of the returns investing in share market $(15 \%)$. 


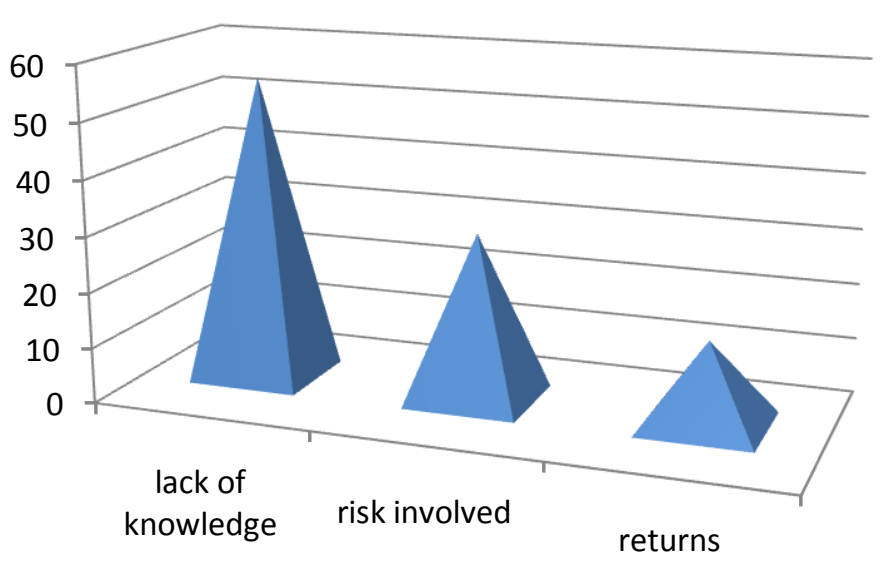

The Investment Option Which Gives More Returns.

Among the respondents the investment options which gives more returns is investment in share market $(40 \%)$, followed by real estate (15\%), mutual funds(20\%), insurance(15\%), bank deposit(5\%) and post office deposit(5\%).

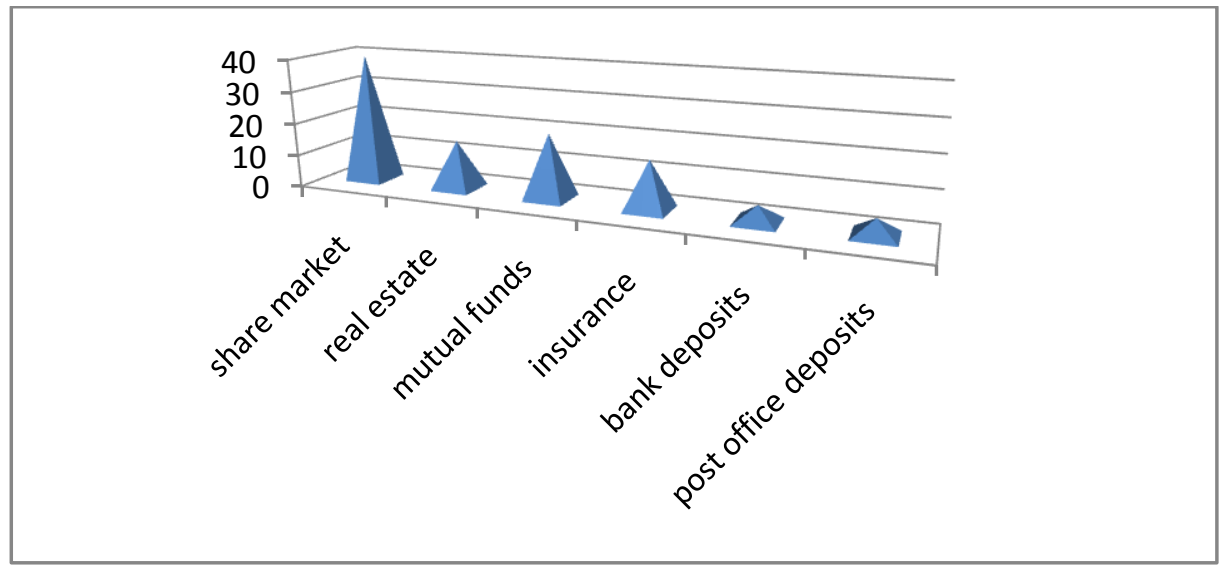

\section{Conclusion:-}

The study on preferred investment choices has been undertaken with the objective, to analyze the investment choice of people in Hoshiarpur city. Analysis of the study was undertaken with the help of survey conducted. After analysis and interpretation of data it is concluded that some respondents are not much aware about various investment choices and also not much aware about the investing pattern in stock market, equity etc. The study is conducted by taking a limited number of sample sizes. There might be a chance that the preference of the respondents may be different because of difference in their awareness level, income level etc. All the age groups among my respondents give more importance to invest in bank deposit and Insurance. Income level of a respondent is an important factor which affects investment portfolio of the respondent. Respondents are more aware about various investment avenues like insurance, bank deposits, small savings like post office savings etc. Every individual should be made aware about various investment avenues, its importance, advantages etc for a secured future and also many more reasons. Though various new avenues are introduced for investment purposes, investors in rural and urban area still prefer bank deposits. The major reason for selecting this investment is owing to safety and security. A planned marketing approach, covering customer awareness, offering better value with a high and constant return to the investors and every effort may be made to draw the rural sector into the mainstream of national economic development. A constant effort is essential to promote the savings and investments behaviour at both rural and urban investors to enrich the total economy. The results of the study indicate that the investors prefer to invest only in safer avenues.

\section{Reference:-}

1. Preeti Singh, "Investment Management” Himalaya Publishing House, New Delhi, 2006. 
2. Rustagi R.P, "Investment Management" Investment Analysis and Portfolio Management", Sultan Chand and Sons, New Delhi, 2007.

3. Vashisht A. K, "Investment Management and Stock Market", Deep and Deep Publishing House, New Delhi, 2005.

4. Bhalla V.K, "Investment Management", S.Chand and company Ltd, New Delhi, 2004.

5. Prasanna Chandra "Managing Investments", Tata- McGraw Hill publishing company Limited, New Delhi, 1998 